Original Research Article

\title{
Bridging the Gaps Between Students' Prior Knowledge and Skills in Writing and the Expected Thesis Outcomes
}

\author{
Restu Mufanti ${ }^{1 *}(\mathrm{D})$, Andi Susilo ${ }^{2,3}$ \\ ${ }^{1}$ Faculty of Teacher Training and Education, Universitas Muhammadiyah Ponorogo \\ J1. Budi Utomo No. 10 Ponorogo, East Java, Indonesia, 63471 \\ ${ }^{2}$ School of Humanities and Communication Arts, 2 Bullecourt Avenue, Milperra NSW 2214, Australia \\ ${ }^{3}$ Faculty of Tarbiyah, IAIN Ponorogo, J1. Pramuka no. 156, Ponorogo, East Java, Indonesia, 63471
}

Article History: Received 31 August 2017; Accepted 20 September 2017; Published 5 October 2017

\begin{abstract}
This research aimed to seek the light on how the advisors made a use of feedback during supervisory panel and find out how different ways and types of feedback impacted on student-writers' thesis outcomes. Qualitative study was applied by involving three tenured lecturers at College of Islamic Studies, in Java as the research subjects. Two data collection techniques were applied, such as interview and documentation, to trace evidence on what types of feedback used, how students noticed, and how they impacted on subsequent drafts. This study revealed that indirect feedback using error codes and commentary was the most frequent form used during the advisory session. However, the mere use of feedback could only serve a short-term impact on the development of writing, and even it seemed only to spoon-feed them which could create burdens in writing. It was quite evident that engaging them in such self-regulated and interdependence group works, through problem-solving discussion and peer review, was much worthier as compared to only ask them to process the feedback themselves.
\end{abstract}

Keywords: Corrective feedback; problem-solving skill; peer review; thesis writing

HOW TO CITE: Mufanti, R. \& Susilo, A. (2017). Bridging the Gaps Between Students' Prior Knowledge and Skills in Writing and the Expected Thesis Outcomes. JEES (Journal of English Educators Society), 2(2). 101-118. doi:http://doi.org.10.21070/jees.v2i2.982.

\section{Introduction}

Thesis writing is one of the scientific papers that should be composed by undergraduate students in Indonesia, including in the college of Islamic studies, as a compulsory requirement to complete their degree. Fundamentally, it serves basic knowledge, skills, and experiences in research that can help them solve academic problems scientifically and make reports on the process and results of study to develop science. With the assistance and feedback from advisors, they are required to be able to access information and references from various sources, organize and make a use of them to support ideas, as well as to articulate their genuine ideas in order to produce cogent and coherence thesis reports. While advisors' feedback may be of great importance to assist them in writing theses, the pitfalls of

*Coresponding author.

E-mail address: mufanti@yahoo.com

Peer reviewed under reponsibility of Universitas Muhammadiyah Sidoarjo.

(C) 2017 Universitas Muhammadiyah Sidoarjo, All right reserved, This is an open access article under

the CC BY license (http://creativecommons.org/licenses/by/4.0/) 
feedback practices are often noticed. Hence, it is undoubtedly interesting to examine the strategies and kinds of feedback used by advisors during the supervisory panel and find out the most suitable types or ways that meet particular needs of students in writing research reports, particularly in the context of the college of Islamic studies.

It cannot be denied that most students often have problems in thesis writing, especially when they are demanded to express and develop their own ideas, although they have taken some crucial courses, such as academic writing, advanced grammar, research methodology and other related subjects. Some mistakes and errors have frequently happened in terms of sentence structure, lexis, spelling, content, or coherence between the ideas in paragraphs developed. In response to these problems, feedback is mostly used to assist them in order that they can notice the errors and improve the quality of the written drafts they make. Feedback is given in various types and ways depending on advisors' own preferences or based on students' needs. While some students benefit from getting valuable information about their writing errors and how to deal with those problems, some others may get frustrated from the feedback as they find it hard to understand. Therefore, the effectiveness of corrective feedback in writing becomes one of the controversial issues that never ceases discussed by advisors as well as attracting much attention of researchers.

Generally, it is widely believed that feedback plays an important role in a negotiation effort to help students produce a better piece of writing. In this void, direct or indirect corrective feedback is mostly used to improve the quality of students' writing from various aspects, such as content, lexis, grammar, organization, referencing, and other related components in writing thesis. Some studies have noted that corrective feedback is effective to help them improve their written works (Sheen, 2007; Bitchener, 2008; Bitchener \& Knoch, 2008). It is reported that students who are given feedback have better skills in improving the subsequent errors compared with those who are not (Ferris, 1999). In fact, if the feedback is obviously noticed and easily understood by students, it is likely worth to assist them to increase their awareness in writing and develop their thesis reports. Shortly, feedback is necessarily used by advisors in order that students know the mistakes they make and help them revise their written works.

While some believe that students benefit from corrective feedback, however, it is likely hard to justify to what extent the feedback significantly contributes to the development of students' thesis writing and improves their problem-solving skills. In fact, it is quite often found that students are struggling to process feedback and they encounter problems how to 
fix up the mistakes in their writing based on the feedback they have received from advisors. Several studies indicate that feedback is empirically ineffective (Hyland \& Hyland, 2006; Russell \& Spada, 2006) and even destructive to the writing skills of learners (Truscott, 1996). It is the case that students occasionally make mistakes in the same areas in their subsequent drafts of writing even though they have received feedback. Moreover, the drawback is also noticed as the amount of feedback can make them under pressure, and the result is predictable as they might postpone writing, commit plagiarism, and get depressed or even drop out.

Reflecting upon some studies above, it seems that research on feedback is still inconclusive. The inconsistency of findings is inevitable and this is mainly caused by the inconsistency of the design or research methodology used in those studies (Gue'nette, 2007). This may happen because this issue involves at least three main inter-related factors which are not constant, such as students as the feedback users, advisors as the subjects, and the feedback itself. The failure in noticing feedback can rely on students. Some problems faced by students in processing feedback have been widely recognized, such as lack of writing skills and practices, insufficiency of grammar mastery, inability to conduct research or inadequacy of critical thinking and effort to solving writing problems. Besides, advisors' ways or techniques in providing feedback may potentially influence whether the feedback is comprehensible or not for students to process. Moreover, types of feedback may also serve as a predetermining factor as particular feedback can be preferable at certain context as compared to another type.

Regardless of the pitfalls of feedback reported by some studies above, it is believed that corrective feedback is of great importance for students. Feedback can assist them to know the flaws or errors they make, such as in terms of sentence structure, content, punctuation, or research methods, and assist them to revise and develop their thesis writing. Furthermore, it serves also as a medium used by advisors to negotiate meaning with students towards their writing, make any important confirmation or clarification, and provide valuable suggestion to improve the quality of their theses.

However, feedback should be adjusted in such ways, so that it can fit in students' needs in writing and meet with the particular condition. In one of State Islamic Colleges in East Java, for instance, there has been found huge gaps between the prior knowledge of thesis writing among the majority of student-researchers and the requirement of thesis outcomes they should make with a short target of maximum submission date. Moreover, a single supervisor policy has been established where the advisor should assure their theses writing in 
all facets, such as language, mechanical aspects, literature review, research design and other related aspects. Accordingly, the policy has influenced the supervision process and the quality of thesis reports composed by students. Besides, feedback serves as an important role during the supervision panel and it has been given in various ways.

While students' prior knowledge in writing and research skills are likely to become problematic issues in the supervisory process, the advisors' ways of giving feedback might be more crucial to investigate. Hence, this study examined the strategies and kinds of feedback used by the advisors to assist students to write research reports during the supervisory panel. In particular, it attempted to know how different ways and types of feedback impact on students' thesis outcomes.

\section{Methods}

A qualitative approach was applied in this present study as it provides ample opportunities to depict and describe the behavior of the subjects in giving feedback in greater depth, and their perspectives could be maintained to complement the data obtained (McMillan, 2008). This study was conducted in the second semester of 2015/2016 academic year, and it involved three tenured English lecturers and advisors (US, PR, and WK) in one of Islamic State University in developing area of East Java. The data obtained were in the forms of words, phrases, and sentences related to the types and tactics used by the advisors in providing feedback on the students' drafts of thesis and factors to be considered to apply the feedback.

To obtain the required data, two data collection techniques were applied, such as interviews and documentation. Semi-structured face-to-face interview format was used in order to ensure that the interview activities could run more flexible, create interest and involvement of the subject, and obtain the data in greater depth (Robson, 2000). The interview was conducted with the three subjects in this study at their offices, and each subject was interviewed separately. They were asked based on the list of questions that had been designed related to the feedback practices. To get deeper and more comprehensive answers about the types and ways of feedback given by the interviewees during supervisory panels, questions were detailed to complement, clarify and specify the data, and then any information given by the subjects was noted. In the interview process, the researchers did not use a tape recorder because in some respects it could put pressure on the subject, affect their openness in providing information, and reduce the validity and consistency of the data obtained. 
Moreover, this study also used documentation to complement the data generated from the interview. Some students' thesis drafts were taken to trace some shreds of evidences, particularly on the types of feedback given, the way how students noticed them, and the impact on their subsequent drafts of revision. The technique was conducted by carefully reading and analyzing the feedback given prior to students' written works on the drafts and the correction made by them as the responses of the feedback provided. To make it easy in recording the data, a noticing table, adopted from Mufanti (2012), was used to trace students' noticing process in feedback.

After the data related to the research subjects' feedback strategies and consideration factors were collected, the data were analyzed qualitatively. The data analysis included a series of activities, such as identifying data patterns, finding the relationships among the data, making a detailed explanation and interpretation as well as generalizing the findings based on the theoretical basis used in this study. In this study, the data obtained were analyzed in depth to explain the research problems through three stages of interactive analysis process adopted from Miles, Huberman, \& Saldaña (1994), namely data reduction, data display and conclusion drawing.

Data reduction was a process of selecting, focusing, simplifying, summarizing and transforming data from the field notes or transcripts of conversations. In this study, the data collected from interviews with the subjects were sorted and classified by gathering the similar information with the data from the document observation. As a result, it was obtained the detailed and focused data to ease the researchers to conduct further analysis. After the reduction process of the data was done, the next step was data display. In this phase, the reduced data was then compiled, integrated, and systematically collected and presented. Furthermore, the data were then collated and interpreted based on the theoretical basis and the formulation of the problems to make a conclusion of the study. Once the data was presented and interpretation was done, the final stage of the analytical work was drawing a conclusion. In this final stage, the research findings were cross-checked out with the existing theories and related previous studies to draw conclusions.

\section{Findings and Discussion}

Results of the interview and document analysis showed that most of the subjects relied on the use of feedback to help students noticing the errors they made and improving the quality of writing. While different subjects might make a use of feedback in different ways, 
corrective feedback was the preferable form applied during a supervisory panel. In addition, this type of feedback was given in various forms, either indirect or direct modes, depending on particular needs or circumstances.

The document analysis revealed that indirect corrective feedback was more frequently used as compared to the direct form. In this case, error correction was provided by advisors using error codes or signs. To indicate where the error existed, some tricks were done, such as by underlining, circling, or putting an error code over the error. The codes were placed within the words or phrases, between the margins or on the right or left of the margins, and mostly they were written in blue or red to ease students find where the error was and identify what types of mistakes they made.

Some common error codes were such as:

- $\mathrm{Ag}$ - to indicate an agreement error,

- Art - misuse of article,

- F-wrong form of the word,

- W - error in using word choices,

- $\mathrm{L}$ - to show problem with linking words,

- C - collocation error,

- $\mathrm{S}$ - spelling error,

- $\mathrm{P}$ - punctuation error,

- $\mathrm{R}$ - wrong register, i.e., too informal

Besides, some signs were also used to indicate the errors, such as:

- $\wedge$ - to indicate that there was missing word or expression,

- $[(\ldots)]$ - unnecessary word, could be omitted or to show the words referred to in a footnote,

- ? - the phrase or clause were confusing, could not be understood or was not logical,

- [underlined Phrases] - Syntax was out of control,

- [delete or delete] - delete the unnecessary word or phrase, and other related marks.

The extent to which the error codes were used and how they were given towards their writing errors were exemplified in the following excerpts. Three excerpts below were respectively taken from student-writers' thesis drafts (IS, RI and WI).

Excerpt 1 
Therefore it needs a new technique to teach vocabulary and make students interested in Ar $P L \wedge$ vocabulary and make them can memorize the vocabulary easily, so the resercher interested $=$ in conducted the research

Excerpt 2

Speaking is a skill which deserves attention every bit as much as literary skill, in foreign languages. Our learners often need to be able to speak with confidence in order to carry out many of their most basic transactions.

\section{Excerpt 3}

It means that students must understand well about the text. If we master reading skill, we can easy to get information and tell something to other.

Excerpt 1 showed that indirect corrective feedback was given in the form of codes to assist students to notice the errors. It was obvious that the sentence was quite hard to understand as it consisted of some different ideas with a lot of errors in grammar. For instance, the advisor marked [W] to assign students to replace the word 'new' because this word was unlikely appropriate to modify the term 'technique' as the writers did not offer really concurrent method. This indirectly suggested the writer replace the word with a more appropriate term, e.g., alternative technique. In addition, another error codes were used, such as 'Art' to show the wrong use of articles; 'P' to mark punctuation error; the symbol L to indicate that the linking word was wrong; marker $[\wedge]$ to show that there was missing word (be); and ' $F$ ' to mark the error in term of word formation in which it should be present participle 'conducting'. In addition, the underline marker of the phrase 'teach vocabulary and the make students interested in vocabulary and make them can memorize' was to indicate that the clause was difficult to understand as a syntax error.

Furthermore, in excerpt 2 RI made a very basic error in the sentence structure which caused the sentence hard to interpret. Some error codes were given prior to the errors to help her easily find where the errors were - for instances, ' $\mathrm{P}$ ' to show error in punctuation, ' $\mathrm{W}$ ' to avoid using personal reference and to indicate error in the word choice, ' $F$ ' to show that the use of noun 'confidence' was not appropriate because the sentence required the adverb 'confidently' and crossing the word '/' to indicate that the sentence did not require the 
preposition 'with'. Since the sentence contained several serious errors particularly on syntax, the error code '?' was given in effort that the writer realized this problem. There were not much other error codes given although the sentence consisted other various errors.

Similarly, Excerpt 3 presents an indirect form of feedback towards WI's draft. It seemed that the sentence contained error particularly in term of sentence structure which might be affected by the writer's knowledge of her first language. The phrase can easy to get information $h$ had inverted wording and did not require a preposition for its auxiliary 'can'. Besides, feedback was also given to suggest the writer to avoid using personal reference.

Moreover, indirect feedback was also used in the form of comments. This type of feedback was subsequently given when the advisors found that students missed major information to include in writing. The comments were sometimes written in the left/ right margins or even on the backside of the paper. The advisors commented on the students' writing to clarify or suggest to improve the draft.

\section{Excerpt 4.}

(2)

1. What kind of language learning problems that occur in joining speaking class at eleventh grade students of Al-Mawaddah?

2. What is the causes of language learning problems that occur in joining speaking class at eleventh grade students of Al-Mawaddah?
(2) Write paragraphs that problematize this study. They can include theory or empirical findings that can drive your ideas to the problems of this study.

Excerpt 4 highlights IS's draft where she got feedback in the form of a comment from the advisor. It showed that the advisor wanted her to write the introductory of paragraph headings that could well explain the background of statements of the problem. This type of comment was beneficial for guiding her to improve the draft as it provided detail information what to write and how she should do it.

Besides, the comment was also given when the advisors found that the errors were complex as illustrated in the excerpt below. 
Excerpt 5

... Speaking is a crucial part of foreign language learning and teaching. (5) Despite it's importance, for many grades, teaching speaking has been undervalued and English teachers have continued to teach speaking just as a repetition of drills or dialogues. However, today's world requires that the goal of teaching speaking should improve students' communicative circumstance...

\section{Comentary}

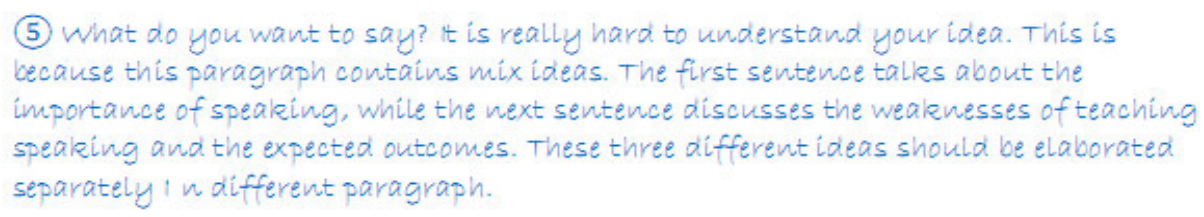

Excerpt 5 presents the instance of comment from an advisor towards ST's draft where the sentence contained complex errors. The sentence consisted of mixed ideas with poor grammatical structure and grammar. In response to this, the advisor underlined the most problematic sentence to indicate the error and provided comment under the margin to help them identify the problem.

While the results revealed that indirect feedback was dominantly used by the advisors, direct feedback was given some of the time during a supervisory panel. The result of the document showed that this direct feedback was frequently given in students' former documents, whereas this immediate correction was found little of the time in later drafts.

Excerpt 6

Teachers is suggested to

The teacher mustapply the best method to help students improve listening the effective appropriate

skill in the classroom.

Excerpt 6 illustrates the instance of immediate correction given by the advisor on IM's draft. This form of feedback was simply used by replacing the incorrect forms of words with the correct ones. In subsequent writing, direct feedback was also given by reformulating students' sentences.

Overall, feedback was used by the subjects to help and assist students to fix the errors on the drafts and improve the quality of the thesis outcomes. Both indirect and direct forms of feedback were used depending upon students' needs, knowledge in research and proficiency levels. While corrective feedback had been necessarily used by the advisors to increase students' writing accuracy, its effectiveness on improving their skills in writing and 
researching was still questionable as it was frequently found errors on their subsequent writing. Major pitfalls of feedback were noticed and these needed to be further analysed.

\section{Factors that Impact on How Students Process Corrective Feedback}

The extent to which feedback providing assistance for students in writing has been widely recognized. Corrective feedback is essentially given to help them know their errors and refine writing problems. Whilst the benefit is true, there are some drawbacks found in this study. Since students had different levels of language proficiency, writing experiences, or research skills, they likely processed the feedback in different ways.

One of the most factors which affected students to respond feedback accurately was that the level of proficiency in English. High-proficient students (HPS) might be better able to process the feedback they received from advisors as compared to low-proficient students (LPS). With their English skills, in fact, HPS could notice the gaps existing on their writing by observing the indicated errors more easily than those of what LPS did and this benefitted them to revise the errors in the appropriate way based on the feedback. On the other hand, with the lack of English skills, LPS might find it difficult to process any particular feedback and resolve their problems.

Excerpt 7

\section{Advisor Feedback: Teacher asks students to read the text individually, they should discuss the questions in the group. \\ Revised Version : Teacher asks students to read the text and then should discuss the questions in the group.}

Excerpt 7 presents the instance where LPS unsuccessfully process the feedback. It was obvious that she did not make any revision on the tick code, and it appeared that she failed to use the article. While direct feedback gave a clear indication of the error in prepositional use (about), the indirect one seemed unrevealed. The lack of grammar knowledge might cause them process the feedback improperly where she made an unintended change.

Some feedback might be comprehensible enough to notice, so students could reveal the case. However, it could be also the case that the feedback was definitely hard to understand which caused them processed incorrectly or even simply ignored them.

Excerpt 8

Advisor feedback : Students of Junior high school in especially in the remote area, their English is very weak and most of them cannot speak fluently because they did not practice it regularly. (the idea is not clearly stated.

$11 C$ Rearrange the sentence by using a clear subject, verb and object) 
Except 8 illustrates the extent to which a student fails to process indirect feedback accurately.

The revised version showed that the writer was unable to catch up the commentary point given by the advisor, as a result, the revised sentence she made was problematic as it contained errors in term of sentence structure as well as the idea. This seemed that little input could be noticed from the feedback given and perhaps their lack ability in writing the topic sentence causing the feedback could not be revealed. Shortly, irrespective of student proficiency levels, it was reasonable to state that the quality of feedback by its own could determine whether it was comprehensible for students or not.

Moreover, students' prior knowledge related to the topic or research methodology can also affect on how they process the feedback and revise their subsequent writing.

Excerpt 9

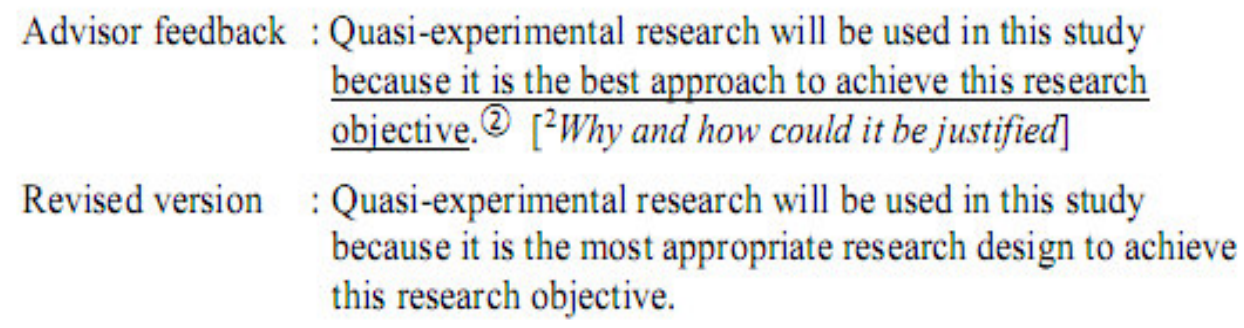

Excerpt 9 shows the data that students' background knowledge may impact on how they process the feedback and revise their draft. It was obvious that the writer attempted to make a change on the underlined phrase with regards to the comment given by the advisor. A sentence reformulation was made in the subordinate clause and a change on lexical choice ('the best approach' changed to 'the most appropriate research design') was done, whereas the writer overlooked the feedback and did not provide any supporting reasons to justify her writing. This problem happened not only because of the writer's lack of writing skill or grammar but also due to her lack of background knowledge about the research methodology since she could not provide any justification or reasoning to respond the feedback she received.

The extent to which corrective feedback was effective or not to assist students to notice the errors and improve the accuracy of their subsequent drafts remained inconclusive. There were some major factors that could influence the level of its effectiveness, such as language proficiency levels, writing experiences, and background knowledge and research skills. Besides, another significant finding was that students' critical thinking and reasoning skills might also considerably contribute to increasing awareness in realizing the errors and 
fix the problems based on the feedback they received. It was reasonable to justify that students who had engaged more actively with the advisors or peers to discuss their writing problems or the feedback they received were better able to revise their subsequent drafts than those who were not. They were likely more cognizant of the existing errors in the drafts and having a self-directed awareness to respond it properly. The feedback served them valuable information about what or how they should do, and such high order thinking and reasoning skills assisted them to fix the errors and helped them to elaborate ideas.

To sum up, while such corrective feedback was beneficial to inform students the problematic issues in writing or to serve immediate correction, this effort seemed only to provide short-term impact. Some drawbacks on the use of corrective feedback, such as making similar mistakes in subsequent writing, ignoring the feedback, or making unintended changes, showed that this kind of feedback only contributed little to the students' development of writing skills, high order thinking, or problem-solving skills. Moreover, the finding found that engaging students in such problem-solving-discussion among peers in regular basis could better able increase their awareness in responding the advisors' feedback and help them improve the quality of their drafts.

\section{Engaging student-writers in such problem-solving discussion and Peer Review}

It could not be denied that corrective feedback played important role in assisting students to develop their thesis drafts. However, the mere use of corrective feedback might also result in negative ways, such as having less awareness to analyze their own mistakes, lacking critical analysis skill, depending much on the advisors' feedback, encountering similar errors in subsequent writing, causing confusion and frustration, and other related burdens. Realizing that corrective feedback alone could serve only sort-term-impacts on students' drafts and writing skills, a valuable measure had been applied by some of the research subjects to overcome the problems that was by involving them to participate actively in such problem-solving discussion and peer review session.

Engaging students in such problem-solving discussion and peer review benefitted them from being highly critical of the writing problems they encountered and meaning negotiation. By involving students in a small group discussion, they had a wide of opportunities to share their problems in writing, get the suggestion from various point of views, and also learn from other works. It was worthy to work in a group discussing the feedback as they could notice the errors more comprehensively and fix them more accurately as compared to work alone. Moreover, students got great chances to negotiate their writing 
problems deliberately and this was beneficial to increase their critical analysis skills. As a result, it was possible to state that students could resolve more writing problems and increase the quality of their drafts.

To engage them in such problem-solving group and peer review, there were some stages to do. Firstly, several training was conducted in advance and students were grouped. A reflective feedback was given by using utilizing the errors made by the group, for instance focusing on subject-verb agreement, as the sources of discussion. In turn, students were asked to present their writing problems to be discussed in the group with the advisors' assistances. While one presented, the other members were required to pay attention and give suggestions. In order to strengthen their comprehension, clarification was provided by the advisors. Basing on the suggestion, students were assigned revise the drafts.

Peer review, in addition, was done to help students learn from each other's strengths and weaknesses. Students were assigned to regulate peer review session independently with regard to the peer review training they got beforehand. To ensure that small group discussion and peer review run effectively, the advisors monitored and checked the progress while asking for their improvement.

In sum, engaging students in both problem-solving group and peer review benefitted them from several positive effects, such as increasing awareness in processing feedback, having more time for meaning negotiation which led them to the increase of comprehension, enhancing critical analysis skills, and improving the accuracy and the quality of writing. While such efforts seemed too complicated and cost considerable time and energy as very tight schedule occupied, it was likely the most reliable measure that the research subjects could do in order that the feedback could be comprehensible for students and they could improve the quality of their thesis writing.

\section{Discussion}

The present study was carried out in order to figure out how the research subjects made a use of feedback to bridge the existing gaps between student-writers' ability in thesis writing and the expected thesis outcome they should make within a short time period. In particular, this research examined the most common feedback used by the advisors in a single-advisor-context, and how different ways and types of feedback impact on students' thesis outcomes.

Most significantly, it was found that corrective feedback, either indirect or direct form, was frequently used. Since it is much easier to maintain, indirect corrective feedback is 
preferable than other types. It is provided by underlining, circling, or putting error codes or markers over the errors to indicate where they are. In responding to more sophisticated problems, indirect feedback with commentary is given to guide the students what and how they should revise the problems. This is in line with Hyland's suggestion (1990: 283) that the writer can see how someone actually responds to their writing as it develops, where an idea gets across, where a confusion arises, where logic or structure breaks down.

While the thesis supervisory process relied more on using corrective feedback to help students recognize the errors and improve writing accuracy, the finding revealed that the mere use of it, particularly in the direct way, could serve only short-term effect on students' writing development. Some essential abilities that students might need to have in writing and researching, such as critical analysis and problem-solving skill, did not increase. Although corrective feedback was given, students tended to make similar mistakes in their subsequent writing, ignore feedback, had a self-awareness to analyze their own mistakes, and rely solely on the advisors' feedback.

Furthermore, since not every feedback could be comprehensible and processed by students, it was possible that they had negative attitudes towards the feedback they received. When analyzed, it is quite evident that the mere use of corrective feedback suffers from several major drawbacks, such as having less awareness to analyze own mistakes, lacking critical analysis skill, counting on the advisors' feedback (Truscott, 1996).

Interestingly, corrective feedback was still somewhat essential and most students preferred to have it. However, it is likely hard to justify what and how feedback is comprehensible and meaningful for students. The finding revealed that there were some considerations used in giving feedback in order that it could satisfy most students, such as they should be aware of when and how to give it, type of errors and its focus, context, students' proficiency level, and preferences, and this is also asserted by Mufanti (2014). These considerations are reasonable since each student has different noticing skill in processing corrective feedback, encounters different writing problems, and processes the corrective feedback differently as well. Therefore, the type and the form of errors should be considered when giving the feedback, for instance, in the first draft, feedback is only focused on the content, and then it turns to grammar and lexis as the focus.

Another finding confirmed the association between engaging students in such negotiation activities, through problem-solving discussion and peer review session, and improvement in processing feedback and writing accuracy. A likely explanation for this is 
that problem-solving discussion and peer review provided a wide range of opportunities for students to critically analyses their own or others strengths and weaknesses, and they worked together to solve writing problems and improve the quality of writing.

It is almost certain that feedback can only benefit students if they are involved in such self-regulated and interdependence group work where they can learn from each other. While it seems hard to set up and maintain these activities for a couple of previous sessions, it will be much easier to manage after students engage in several meetings as they were more aware of the importance of group discussion and peer review for themselves. This adds to the study conducted by Min, (2006) into the effects of trained peer review on students' revision types and writing quality.

\section{Conclusions}

Corrective feedback, either direct or indirect form, was inevitably used during a supervisory panel. The findings demonstrated that indirect feedback using error codes was the most frequent form used by advisors and it was occasionally complemented with commentary when they found the writing problems were sophisticated. To make it more beneficial for student-writers, there was some consideration that should be taken into account, such as understanding when and how to give it, type of errors and its focus, context, proficiency level, need of writing and preferences.

However, the mere use of corrective feedback could contribute less and serve shortterm impact on the development of their writing. The excessive use of feedback would only spoon-feed them, as a result it could create burdens in writing, such as ignoring the feedback, having less self-awareness to analyze own mistakes, and counting only on the advisors' feedback. In this void, it was quite evident that engaging them in such self-regulated and interdependence group works was more meaningful and beneficial as compared to only ask them to process it themselves. Therefore, problem-solving discussion and peer review sessions were the most reasonable measure to bridge the existing gaps in thesis writing as they provided huge chances for students to critically analyze their own and other writing and work collaboratively to process the feedback and improve the quality of writing.

This study was influenced by some limitations due to a lack of document analysis with a broader focus of questions and this might not be generalized to other contexts. Further research can involve students' perception of the efficacy of feedback to triangulate the data in order that the consistency of findings can be maintained. 


\section{Acknowledgments}

The research was supported by Directorate for Researches and Community Services,

Directorate General of research Empowerment and Development, Ministry of Research, Technology and Higher Education (KEMENRISTEKDIKTI) in the year of 2015-2016. We are also greatly grateful to the Research and Community Service Institution (LPPM), Universitas Muhammadiyah Ponorogo that facilitate to access the grant. We thank to Institute Agama Islam Negeri Ponorogo who has been our collaborator during the course of this research and we also thank to the lecturers for being the subject of this research so make this research ran well and fluently.

\section{References}

Bitchener, J. (2008). Evidence in support of written corrective feedback. Journal of Second Language Writing, 17, 102-118.

Bitchener, J., \& Knoch, U. (2008). The value of written corrective feedback for migrant and international students. Language Teaching Research, 12(3), 409-431. https://doi.org/10.1177/1362168808089924

Hyland, K. (1990). Providing productive feedback. ELT Journal, 44(4), 279-285. https://doi.org/10.1093/elt/44.4.279

Hyland, K., \& Hyland, F. (2006). Feedback on second language students' writing. Language Teaching, 39(2), 83. https://doi.org/10.1017/S0261444806003399

Miles, M. B., \& Huberman, A. M. (1994). Qualitative Data Analysis (2nd ed.). United States of America: SAGE Publications.

Min, H.-T. (2006). The effects of trained peer review on EFL students' revision types and writing quality. Journal of Second Language Writing, 15(2), 118-141. https://doi.org/10.1016/J.JSLW.2006.01.003

Mufanti, R. (2012). Students' Noticing of Corrective Feedback on Writing. 61st International TEFLIN. State University of Surabaya, Surabaya.

Mufanti, R. (2014). STUDENTS NOTICING OF CORRECTIVE FEEDBACK ON WRITING (Case study for low learner). In Prosiding International 'The 61st TEFLIN International. Solo: UNS. Retrieved from http://eprints.umpo.ac.id/2016/

Robson, C. (2000). Small-Scale Evaluation: Principles and Practice. London: Sage 


\section{Publications.}

Russell, J., \& Spada, N. (2006). The effectiveness of corrective feedback for the acquisition of L2 grammar. (J. M. Norris \& L. Ortega, Eds.), Synthesizing research on language. Amsterdam: Benjamins.

Sheen, Y. (2007). The Effect of Focused Written Corrective Feedback and Language Aptitude on ESL Learners' Acquisition of Articles. TESOL Quarterly, 41(2), 255-283. https://doi.org/10.1002/j.1545-7249.2007.tb00059.x

Truscott, J. (1996). The case against grammar correction in L2 writing classes. Language Learning. Retrieved from http://onlinelibrary.wiley.com/doi/10.1111/j.14671770.1996.tb01238.x/full 
Journal of English Educators Society, 2 (2), October 2017, 101-118

ISSN 2503-3492 (Online)

Journal Homepage: http://ojs.umsida.ac.id/index.php/jees

DOI Link: http://dx.doi.org.10.21070/jees.v2i2.982 